\title{
Possibilities of Training for School Librarians in the Digital Age: A Case Study of "SLiiiC"
}

\author{
Ms. Sumiyo Yokoyama \\ School librarian, Kugayama elementary school \\ 5-18-7 Kugayama, Suginami-Ku \\ Tokyo 168-0082 \\ Japan, \\ sumira@d4.dion.ne.jp
}

Ms. Mitsuko Daisaku

Teacher librarian, Myojo Gakuen elementary school

5-7-7 Inokashira, Mitaka-shi

Tokyo 181-0001

Japan,

mdaisaku@myojogakuen.ac.jp

Ms. Kumiko Noguchi

Lecturer, Yashima Gakuen University

7-42 Sakuragi-cho, Nishi-Ku, Yokohama-shi,

Kanagawa-ken 220-0021

Japan,

noguchi@yashima.ac.jp

\author{
Mr. Fukuji Imai \\ Associate Professor, Shirayuri University \\ 1-25 Midorigaoka, chofu-shi \\ Tokyo 182-8525 \\ Japan, \\ fukuji@shirayuri.ac.jp
}

\begin{abstract}
:
The purpose of this paper is to indicate the required elements for the training of school librarians, especially public school librarians in Japan. This was done through a case study of SLiiiC (School Libraries Communication Collaboration and Combination)activities that the authors of this paper belong to. Training is important for the school librarians to strengthen their expertise. However, the public school librarians have insufficient opportunities for training
\end{abstract}


provided by their employers. Some of the school librarianship groups provide several different opportunities for the school librarians. Their participation in such training is dependent on their availability and/or financial situation. Besides that, almost all the school librarians are the sole worker in their school library. Therefore, the training is important as an opportunity to share information with sole-charge school librarians and to build a network of contacts.

SLiiiC(http://www.sliiic.org/) was established in 2005 as a voluntary group to try and solve these problems as mentioned above. We created our own website to provide content for training and communication. We are making useful content on our website, for example, technique for repairing books, tips on offering orientation for students, the collection of links about the school libraries, and so on. Also we are relaying learning programs on a video hosting service and SNS. The aim of these activities is to provide information about skills and knowledge to those school librarians who are living in distant places or are isolated. We have also arranged means for them to get together, both on the internet and at in-person meetings.

The annual summer event called Summer Work Camp(SWC) provides considerable active learning, not simply attending lectures. For example, we considered "the role of the school library for lifelong education" by learning and applying the World Café method with college students in SWC2015. SLiiiC's aim is to encourage the participants to also maintain their relationships and learning with each other via SNS after attending training programs. With this in mind, we also provided training on how to use twitter(2010) and Ustream(2012).

Based on SLiiiC's collaborative work and experience, we would like to point out the following two points according to the main objectives of this proposal. : 1) By the active utilization of the internet, school librarians and staff can learn, regardless of their location. 2) As an element of training, it is necessary to provide various means for maintaining good relationships among participants, both via the internet and at in-person meetings. It will be important to create more training programs to provide school librarians the opportunities to improve themselves and their work while gaining the support of other librarians.

We are planning to show the SLiiiC website in more detail and the history of the SLiiiC project.

Keywords: school librarian, training programs

\section{Biographical note}


Author 1: Sumiyo YOKOYAMA is a school librarian at Kugayama elementary school, Tokyo, Japan; her main interest is providing good support for teaching, active learning and reading education. She is a representative of SLiiiC.

Author 2: Mitsuko DAISAKU has worked as teacher librarian at Myojo Gakuen elementary school in Japan; her main research is inquiry-based learning, information literacy education and learning assessment.

Author 3: Kumiko NOGUCHI has worked as lecturer at Yashima Gakuen University in Japan; her main research is history of reading education.

Author 4: Fukuji IMAI has worked as lecturer at Shirayuri University in Japan; his main research is history of school library. 